\title{
Membrane Enhanced Bioaccessibility Extraction (MEBE) of hydrophobic soil pollutants - Using a semipermeable membrane for separating desorption medium and acceptor solvent
}

Cocovi-Solberg, David J.; Kellner, Astrid; Nørgaard Schmidt, Stine; Loibner, Andreas; Miró, Manuel; Mayer, Philipp

\section{Published in:}

Environmental Pollution

Link to article, DOI:

10.1016/j.envpol.2019.113470

Publication date:

2020

Document Version

Peer reviewed version

Link back to DTU Orbit

Citation (APA):

Cocovi-Solberg, D. J., Kellner, A., Nørgaard Schmidt, S., Loibner, A., Miró, M., \& Mayer, P. (2020). Membrane Enhanced Bioaccessibility Extraction (MEBE) of hydrophobic soil pollutants - Using a semipermeable membrane for separating desorption medium and acceptor solvent. Environmental Pollution, 257, [113470]. https://doi.org/10.1016/j.envpol.2019.113470

\section{General rights}

Copyright and moral rights for the publications made accessible in the public portal are retained by the authors and/or other copyright owners and it is a condition of accessing publications that users recognise and abide by the legal requirements associated with these rights.

- Users may download and print one copy of any publication from the public portal for the purpose of private study or research.

- You may not further distribute the material or use it for any profit-making activity or commercial gain

- You may freely distribute the URL identifying the publication in the public portal 


\section{Journal Pre-proof}

Membrane Enhanced Bioaccessibility Extraction (MEBE) of hydrophobic soil pollutants - Using a semipermeable membrane for separating desorption medium and acceptor solvent

David J. Cocovi-Solberg, Astrid Kellner, Stine N. Schmidt, Andreas Loibner, Manuel

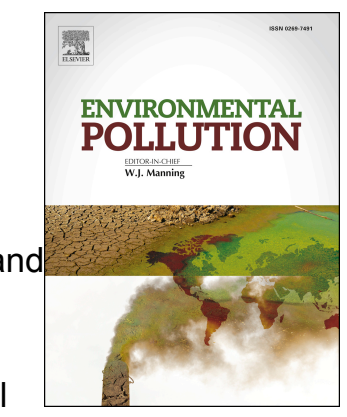
Miró, Philipp Mayer

PII: S0269-7491(19)32997-5

DOI: https://doi.org/10.1016/j.envpol.2019.113470

Reference: ENPO 113470

To appear in: Environmental Pollution

Received Date: 6 June 2019

Revised Date: 5 September 2019

Accepted Date: 21 October 2019

Please cite this article as: Cocovi-Solberg, D.J., Kellner, A., Schmidt, S.N., Loibner, A., Miró, M., Mayer, P., Membrane Enhanced Bioaccessibility Extraction (MEBE) of hydrophobic soil pollutants - Using a semipermeable membrane for separating desorption medium and acceptor solvent, Environmental Pollution (2019), doi: https://doi.org/10.1016/j.envpol.2019.113470.

This is a PDF file of an article that has undergone enhancements after acceptance, such as the addition of a cover page and metadata, and formatting for readability, but it is not yet the definitive version of record. This version will undergo additional copyediting, typesetting and review before it is published in its final form, but we are providing this version to give early visibility of the article. Please note that, during the production process, errors may be discovered which could affect the content, and all legal disclaimers that apply to the journal pertain.

(C) 2019 Published by Elsevier Ltd. 
Membrane Enhanced Bioaccessibility Extraction (MEBE) of hydrophobic soil pollutants - Using a semipermeable membrane for separating desorption medium and acceptor solvent

5 David J. Cocovi-Solberg ${ }^{1,2}$, Astrid Kellner ${ }^{1,3}$, Stine N. Schmidt ${ }^{1}$, Andreas Loibner ${ }^{3}$, Manuel Miró ${ }^{2}$, Philipp Mayer $^{1, *}$

${ }^{1}$ DTU Environment, Technical University of Denmark, Bygningstorvet B115, DK-2800 Kgs. Lyngby, Denmark ${ }^{2}$ FI-TRACE group, Department of Chemistry, University of the Balearic Islands, Carretera de Valldemossa, km 7.5, E-07122 Palma de Mallorca, Spain

${ }^{3}$ University of Natural Resources and Life Sciences Vienna, BOKU, Konrad Lorenz Strasse 20, A-3430 Tulln, Austria

*philm@env.dtu.dk

DCS present address: University of Natural Resources and Life Sciences, BOKU, Muthgasse 18, 1190 Vienna, Austria

SNS present address: National Research Council, US Environmental Protection Agency, National Health and Environmental Effects Research Laboratory, Atlantic Ecology Division, 27 Tarzwell Dr., Narragansett, RI 02882, USA 


\section{ABSTRACT}

Bioaccessibility extractions are increasingly applied to measure the fraction of pollutants in soil, sediment and biochar, which can be released under environmentally or physiologically relevant conditions. However, the bioaccessibility of hydrophobic organic chemicals (HOCs) can be markedly underestimated when the sink capacity of the extraction medium is insufficient. Here, a novel method called "Membrane Enhanced Bioaccessibility Extraction" (MEBE) applies a semipermeable membrane to physically separate an aqueous desorption medium that sets the desorption conditions from an organic medium that serves as acceptor phase and infinite sink. The specific MEBE method combines HOC (1) desorption into a 2-hydroxypropyl- $\beta$ cyclodextrin solution, (2) transfer through a low-density polyethylene (LDPE) membrane and (3) release into ethanol, serving as analytical acceptor phase. The surface to volume ratio within the LDPE membrane is maximized for rapid depletion of desorbed molecules, and the capacity ratio between the acceptor phase and the environmental sample is maximized to achieve infinite sink conditions. Several experiments were conducted for developing, optimizing and pre-testing the method, which was then applied to four soils polluted with polycyclic aromatic hydrocarbons. MEBE minimized sample preparation and yielded a solvent extract readily analyzable by HPLC. This study focused on the proof-of-principle testing of the MEBE concept, which now can be extended and applied to other samples and desorption media. 
Reliable assessment of environmental exposure to hydrophobic organic chemicals (HOCs) from solid matrices requires measurements that go well beyond exhaustive extractions and total concentrations ${ }^{1-7}$. Bioaccessibility tests are increasingly applied for determining the fraction of HOCs that can be released from environmental matrices under environmentally or physiologically relevant conditions. Bioaccessibility describes the mass quantity of a chemical that can become available within a given time span and under given conditions. This accessible portion can be applied to estimate the quantity of the contaminant that can be mobilized and made available for certain processes, such as (bio)degradation and biotic uptake ${ }^{6}$. Typically, bioaccessibility tests involve mild extractions aiming at desorbing the accessible fraction, while avoiding exhaustive extraction and disintegration of the solid matrix ${ }^{8}$. However, during the last 7 years several researchers have shown that the bioaccessibility of HOCs can be markedly underestimated when the capacity of the extraction medium is insufficient for a given sample ${ }^{9-13}$. The traditional approach for avoiding such underestimations has been to increase the liquid volume to solid mass ratio, which for heavy metals often is set to $100 \mathrm{~L} / \mathrm{kg}$. Unfortunately, such volume to mass ratios are insufficient for bioaccessibility extractions of HOCs in solid samples with very high solid to water distribution coefficients

$55\left(K_{D}\right)$, which for polycyclic aromatic hydrocarbons (PAHs) in soot, soil, sediment and biochar can exceed $10^{6}$ $\mathrm{L} / \mathrm{kg}^{2,12,14,15}$.

Several approaches have been reported to ameliorate the sink capacity of bioaccessibility extractions, which usually involve the incorporation of sorptive sinks in a three-phase extraction system ${ }^{10}$ in order to maintain the concentration gradients that drive the desorption process: (1) The so-called 'contaminant $\operatorname{trap}^{\prime 16}$ uses a composite of polydimethylsiloxane (PDMS) and activated carbon as infinite sink, (2) Sorptive Bioaccessibility Extraction (SBE) $)^{9,17}$ applies a long silicone rod with high contact surface area as sorptive sink that allows back-extraction of the analytes and (3) slurry solid-phase extractions utilize poly(diphenylphenylene oxide) (Tenax) or poly(styrene-divinylbenzene) copolymeric (e.g., Amberlite XAD-2) beads as sinks ${ }^{8,18-20}$. However, depletive sampling of HOCs from soils by these sorptive-based procedures is 
not free from drawbacks. Accumulated HOC species cannot be retrieved easily from contaminant traps due to their high retention in the PDMS-activated carbon composite ${ }^{16}$, and the bioaccessible fraction can then only be estimated by subtraction of the non-desorbable pool from the total concentrations, which both must be measured by exhaustive extraction. As for sorptive bioaccessibility extraction with silicone rods (SBE), a large mass of sorbent is needed to ensure a high sorptive capacity and the analytical workflow is lengthened by the back-extraction of target analytes out of the large silicone $\sin ^{9,17}$. Recent research has also demonstrated that SEB with silicone as sink can be insufficient for measurement of accessible PAHs in solid samples with extremely high $K_{D}$ values ${ }^{12}$. Finally, Tenax beads can be difficult and sometimes even impossible to separate properly from the solid matrix in bead-based extractions and dedicated configurations are usually called for ${ }^{21}$.

75 A fundamental paradigm in bioaccessibility extractions is to provide relevant desorption conditions, avoid exhaustive extraction and at the same time ensure an extraction system with sufficiently high sink capacity $^{12}$. Additionally, the desorption from the sample matrix should be the rate limiting step, and thus the transfer of the released molecules to the sink must be faster than the desorption step. Consequently, novel approaches are needed that allow desorption conditions and sink capacity to be varied and set independently, while ensuring fast removal of contaminants from the desorption medium. The present study introduces such an approach, where a semipermeable membrane is applied as physical barrier between two media: (1) The environmental sample is suspended in an aqueous medium that sets the desorption conditions, (2) the membrane is, besides a physical barrier, also the initial sink and conducting medium ${ }^{22}$ for the analytes and (3) an organic solvent serves as the analytical acceptor phase and infinite sink. The desorption thus takes place in a small volume of a mild extraction medium within a flat bag membrane that is submerged in a larger acceptor volume, since this new configuration maximizes the ratio of sink surface area relative to extraction medium volume. This "Membrane Enhanced Bioaccessibility Extraction" (MEBE) concept has several commonalities with the biotic uptake of HOCs sorbed to solid matrices, which generally involves desorption from the matrix and then transfer through a biological 
semipermeable membrane. However, MEBE does not intend or pretend to simulate biological processes. The MEBE method is based on the progress made within analytical chemistry on membrane assisted extraction and cleanup methods, which today can yield solvent extracts that are ready for the direct injection into GC and LC systems ${ }^{23-26}$. The hypotheses of the current study were that MEBE (1) allows setting the desorption conditions in an aqueous desorption medium while maximizing the sink capacity of a solvent acceptor, (2) can yield solvent extracts that are ready for HPLC measurements and (3) is applicable to field contaminated matrices with high $\mathrm{K}_{\mathrm{D}}$ values in a very simple and practical manner.

\section{WORKING PRINCIPLE, DESIGN AND OPTIMIZATION OF MEBE}

The solid environmental sample is suspended in a small volume of 2-hydroxypropyl- $\beta$-cyclodextrin solution

(i.e. the desorption medium, HPCD) within a flat low-density polyethylene (LDPE) bag, which is then carefully sealed and placed in a glass vessel containing a much larger volume of acceptor solvent. The vessel is placed horizontally on a roller mixer during the MEBE process. On a molecular scale, HOCs desorb from the environmental sample and are co-transported by the HPCD as inclusion complexes to the LDPE membrane ${ }^{27}$, which acts as an intermediate sorptive $\operatorname{sink}^{28}$ and thereby maintains the desorption gradient. The HOC molecules then diffuse through the LDPE membrane and partition into the solvent acceptor ${ }^{26}$, which acts as a final sink and in turn maintains the diffusion gradient that drives the diffusive mass transfer of HOCs through the LDPE membrane (see TOC Figure).

First, the current work presents the development and optimization of a MEBE method, including (1) solvent selection, (2) sink volume dimensioning, (3) diffusive mass transfer across the LDPE membrane, (4) agitation mode selection, (5) uptake of solvent through the LDPE membrane and (6) comparison of MEBE with conventional HPCD extraction. Second, this MEBE method was applied to four industrially contaminated soils including samples with expected high $K_{D}$ values and slow desorption kinetics, which set special 
demands on the bioaccessibility extraction system ${ }^{12}$. Results from one soil were compared to recent results obtained by sorptive bioaccessibility extraction.

\section{MATERIALS AND METHODS}

Chemicals and materials. A certified reference material CRM47940 (Standard PAH mixture) was purchased from Sigma-Aldrich. It contained the 16 US EPA priority PAHs at the $10 \mathrm{mg} / \mathrm{L}$ level in acetonitrile. A 20-cm long low-density polyethylene (LDPE) bag was made from a $2.54 \mathrm{~cm}$ wide $\times 70 \mu \mathrm{m}$ thick flat LDPE hose (Brentwood Plastics Inc., St. Louis, MO, USA) by double-hot-sealing. Different qualities of ethanol were used

in the initial experiments, and all final experiments were conducted with ethanol of analytical grade (99.98\%, VWR Chemicals). $\beta$-cyclodextrin (HPCD, 2-hydroxypropyl- $\beta$-cyclodextrin, MW=1437.75 g/mol) was supplied by Wacker-Chemie, Burghausen, Germany. Miglyol 812 (also evaluated as a final sink) is a purified palm oil made of triglycerides (Cremer Oleo, Hamburg, Germany).

Industrially contaminated soils. The initial method development was conducted on a heavily PAH contaminated soil that originated from a landfill in Vienna (Austria), and the second phase of the study was conducted with three additional field contaminated soils that were sampled at individual sites in Vienna. The four soils show varying contamination history, soil characteristics and PAH content (see Table SI1). The soils were sieved below $2 \mathrm{~mm}$ before use. The total organic carbon (TOC) content was quantified using a carbon combustion analyzer (RC612, LECO). Soil pH was measured in $\mathrm{CaCl}_{2}(0.01 \mathrm{~mol} / \mathrm{L})$ suspension, whereas texture was analyzed following the Austrian Standard (ÖNORM $4220^{29}$ ). Ethyl acetate was used for exhaustive extraction of PAHs from the soils. Before analysis, extracts were diluted with methanol (at least 1:3) according to concentration range. Quantification of PAHs was performed on a liquid chromatography system with multiband fluorescence and UV/VIS detection. The method was optimized for the separation 
and a buffer/methanol gradient as mobile phase. Further information can be found in the Supporting Information (SI).

\section{Development of the MEBE method}

Solvent selection. A first experiment was conducted to assess the general compatibility of different solvents with MEBE. Several $20 \mathrm{~cm} \times 2.54 \mathrm{~cm}$ flat LDPE bags were filled with solvents that are known to dissolve lipophilic compounds: 1-hexanol, hexane, 1-octanol, 2,2,4-trimethylpentane, ethyl acetate, ethanol and acetone. Bags with $10 \mathrm{~mL}$ solvent were sealed on both ends, weighted and placed in 50-mL Schott-Duran flasks closed with Teflon-lined caps. The flasks were opened regularly during a 2-week period, and the LDPE bags were checked visually for leakage, membrane swelling, change of appearance and for solvent losses based on gravimetric analysis.

In a second experiment, the mass transfer of four solvents through the LDPE membrane was quantified. 10 $\mathrm{mL}$ of a given solvent were placed in the LDPE bag, which in turn was placed in an open glass jar. The evaporative loss was monitored gravimetrically. Even though this experiment does not reflect experimental conditions of MEBE, it reveals how much of a solvent can pass across the LDPE membrane. The four solvents tested as potential final sinks for MEBE in this mass transfer experiment were: (1) ethanol (inexpensive, green solvent), (2) miglyol oil (purified lipid), (3) methanol (solvent well suited for HPLCanalysis) and (4) acetonitrile (solvent well suited for HPLC-analysis). Based on these two experiments, ethanol was selected as a suitable acceptor medium and sink in all further experiments. 
Sink volume dimensioning. The PAH mass in ethanol was determined for varying acceptor volumes to identify the minimum required volume with sufficient sink capacity, while at the same time ensuring sufficient analytical sensitivity. MEBE devices were filled with $0.5 \mathrm{~g}$ soil (landfill, Vienna) and $2.0 \mathrm{~mL} 75 \mathrm{~g} / \mathrm{L}$ HPCD solution, containing $0.5 \mathrm{~g} / \mathrm{L} \mathrm{NaN}_{3}$ as a biocide to circumvent biotic degradation of organic species. The loaded devices were then immersed in $22-\mathrm{mL}, 100-\mathrm{mL}$ and $1000-\mathrm{mL}$ bottles that contained respectively $5 \mathrm{~mL}, 50 \mathrm{~mL}$ and $500 \mathrm{~mL}$ ethanol, yielding solid to acceptor phase ratios of 1:10, 1:100 and 1:1000. The bottles were shaken on an orbital shaking table at $80 \mathrm{rpm}$ for 28 days (triplicates, protected against light). Aliquots of $100 \mu \mathrm{L}$ ethanol were sampled and analyzed by HPLC at predetermined time points, without replenishing the volume probed.

Diffusive mass transfer across the LDPE membrane. The time required for a quantitative PAH transfer through the LDPE membrane was determined. $100 \mu \mathrm{L}$ CRM47940 (10 mg/L Standard PAH mixture in acetonitrile) was added to the MEBE device (no soil, no HPCD solution), and the PAH transfer into $50 \mathrm{~mL}$ ethanol acceptor phase was monitored over time (triplicates, orbital shaking, $80 \mathrm{rpm}$ ). Aliquots of $100 \mu \mathrm{L}$ ethanol were sampled and analyzed by HPLC at 1, 2, 4, 8, 16, 24, 48 and $96 \mathrm{~h}$ without replenishing the sampled volume. The transfer of each PAH was plotted against time, fitted to a simple first order model and the time to transfer $95 \%$ of the initial mass was estimated.

Agitation mode selection. To determine the best agitation mode, LDPE bags with $0.5 \mathrm{~g}$ soil (landfill, Vienna) were contained in $22-\mathrm{mL}$ vials with $15 \mathrm{~mL}$ ethanol acceptor and subjected to different shaking conditions (triplicates): unshaken, vortex shaking (500 rpm), horizontal rolling (60 rpm) and gentle orbital shaking (80 rpm). Aliquots of $100 \mu \mathrm{L}$ ethanol were sampled and analyzed by HPLC at 2, 4, 8, 24 and $48 \mathrm{~h}$ without replenishing the volume removed during sampling. 
Uptake of solvent through the LDPE membrane. Several parallel MEBE systems were assembled without soil samples, and the mass transfer of ethanol through the LDPE membrane and into the HPCD solution was determined as a function of time. For this purpose, LDPE bags were filled with $2 \mathrm{~mL} \mathrm{HPCD} \mathrm{solution,} \mathrm{sealed}$ and placed in glass jars filled with $50 \mathrm{~mL}$ ethanol. After 1, 2, 4, 7 and $14 \mathrm{~d}$, HPCD solutions from the bags were sampled and analyzed for ethanol content using GC-FID. This experiment was conducted in pentaplicate.

\section{Comparison of MEBE with conventional HPCD extraction}

The mass transfer kinetics of the proposed MEBE method was determined and then compared against an extraction with the same mobilization medium but without a $\operatorname{sink} \mathrm{k}^{30,31}$. To this end, $0.5 \mathrm{~g}$ soil (landfill, Vienna) was introduced into a $20 \mathrm{~cm} \times 2.54 \mathrm{~cm}$ flat LDPE bag along with $2 \mathrm{~mL} 75 \mathrm{~g} / \mathrm{L} \mathrm{HPCD}$ and $0.5 \mathrm{~g} / \mathrm{L}$ $\mathrm{NaN}_{3}$. The sealed bag was transferred into a $100-\mathrm{mL}$ Schott-Duran bottle and $50 \mathrm{~mL}$ ethanol was added. The bottles were closed and then placed on an orbital shaking table at $80 \mathrm{rpm}$. Aliquots of $100 \mu \mathrm{L}$ ethanol were sampled and transferred to micro-inserts in 1.5-mL HPLC vials at 1, 2, 4, 8, $16 \mathrm{~h}$ and 1, 2, 4, 7 and $14 \mathrm{~d}$, without replenishing the withdrawn volume, and analyzed by HPLC without further treatment. This

195 experiment was conducted in triplicate. In parallel, $0.5 \mathrm{~g}$ of the same soil was incubated for 28 days in a 100-mL Schott-Duran bottle with $50 \mathrm{~mL} 75 \mathrm{~g} / \mathrm{L} \mathrm{HPCD}$ solution containing $0.5 \mathrm{~g} / \mathrm{L} \mathrm{NaN}$ and sampled at the same time intervals as for the MEBE method. In every sampling cycle, approximately $1 \mathrm{~mL}$ of the HPCD medium was sampled with a 1-mL syringe, filtered through a $0.45-\mu \mathrm{m}$ nylon filter into a HPLC vial until approximately $100 \mu \mathrm{L}$ clean extract was transferred to the autosampler vial. The syringe plunger was then pulled back to recover the non-filtered extract and retained soil particles for returning them to the SchottDuran bottle. In this way, only approximately $100 \mu \mathrm{L}$ extract were collected in every discrete sampling step and only a minute quantity of soil was lost. 


\section{Application of MEBE to industrially polluted soils}

In the second phase of the study, MEBE was applied for determining the PAH bioaccessibility in Vienna landfill soil and three additional industrially contaminated soils from urban sites in Vienna, Austria (Table SI1). For comparing the extraction efficiency of MEBE and conventional HPCD extraction, all four industrially contaminated soils were subjected to HPCD extraction, generally following the procedure given above. In this experiment, samples of HPCD solution ( $1 \mathrm{~mL}$ ) were taken after 1, 2, 4 and $6 \mathrm{~d}$ and filtered using PTFE syringe filters prior to dilution with methanol (1:2) and HPLC analysis of PAHs (details given in SI).

Approximately one week before the experiments, 22-cm long LDPE devices were prepared, sealed twice on each end to form bags and soaked in excess ethanol for cleaning. The bags were removed from the ethanol cleaning solution, dried at room temperature and opened at one end. Dry soil $(0.5 \mathrm{~g})$ was placed in each bag while avoiding soil particles on the top end, as this had earlier led to imperfect sealing with small leaks in some replicate bags. $2 \mathrm{~mL}$ HPCD solution $(75 \mathrm{~g} / \mathrm{L}$ ) was added to the soil in the bags (avoiding also drops at the top end). Bigger air pads were removed manually, the bags were sealed again at the top and then visually checked for leakage. Bags were wrapped up and placed individually in $60-\mathrm{mL}$ amber glass jars. The jars were filled with $50 \mathrm{~mL}$ ethanol each, closed tight and placed horizontally on roller tables operating at $60 \mathrm{rpm}$. These experiments were conducted in pentaplicate for each of the four soils, which resulted in a total of 20 jars for this experiment. After 1, 2, 4, 6, 9 and $14 \mathrm{~d}, 1 \mathrm{~mL}$ of the ethanol was sampled from each jar and transferred to a 2-mL vial. The bioaccessible PAH mass in these ethanol acceptor solutions, as well as the total PAH mass in the ethyl acetate extracts, were measured with the same HPLC method to avoid that the use of different analytical methods would confound the calculation of accessible fractions. 


\section{Partitioning calculations}

The governing partition coefficients of representative PAHs were determined with the UFZ-LSER database ${ }^{32}$. The ethanol to poly(dimethylsiloxane) partition ratios ( $\left.\mathrm{K}_{\mathrm{EtOH}, \mathrm{PDMS}}\right)$ were determined to relate the acceptor capacity of MEBE to the acceptor capacity of sorptive bioaccessibility extraction methods with a silicone sink. The partition ratios between "10-20\% ethanol solution" and water ( $\log \mathrm{x}_{\mathrm{x} \in \mathrm{tOH}, \mathrm{w}}$ ) were used to quantify the effect of ethanol diffusion into the membrane bag on the MEBE process.

\section{RESULTS AND DISCUSSION}

\section{Solvent loss experiments and solvent selection}

235 In MEBE, it is crucial that the permeation of the acceptor solvent through the membrane is kept low to minimize solvent transfer to the aqueous desorption solution, since the solvent could potentially facilitate the desorption process. During the first solvent loss experiment, the losses of ethyl acetate, hexane and acetone were higher than for the other more polar solvents (results not shown). The surface of the bag exposed to 2,2,4-trimethylpentane was slightly cloudy after 7 days, possibly indicating an effect of this solvent on the LDPE membrane. All these solvents were thus discarded as acceptor solvent. During the second solvent loss experiment, the loss of acetonitrile, methanol and ethanol was linear with time, with the lowest loss observed for ethanol ( $0.1 \%$ in two weeks). For miglyol oil, no loss was detected after 6 days $(<0.01 \%)$. Finally, ethanol was chosen as acceptor solvent in the present study since it combined (1) good availability of pure grade at low cost, (2) a good environmental profile, (3) low toxicity and (4) allows direct injection on reversed-phase HPLC with no further clean-up of the extract. To the contrary, the PAH quantification in miglyol extracts with HPLC would need a substantial clean-up step or fractionation protocol for the isolation of PAHs before analysis ${ }^{33}$. 


\section{Sink Dimensioning}

The aim of this assay was to determine a suitable acceptor volume that is practical and provides sufficient sink capacity. The PAH masses transferred from $0.5 \mathrm{~g}$ soil to 5,50 and $500 \mathrm{~mL}$ ethanol after 8 days are shown in Figure 1. The extracted masses of 2-4 ringed PAHs did not differ markedly between parallel MEBE extractions with varying acceptor volume and thus varying sink capacity (Figure 1). To the contrary, the masses of 5 and 6 ringed PAHs were systematically lower in $5 \mathrm{~mL}$ compared to 50 and $500 \mathrm{~mL}$ acceptor solution, which indicated insufficient sink capacity of $5 \mathrm{~mL}$ acceptor volume. The PAH mass of all measured 2-6 ringed PAHs was similar or higher in $50 \mathrm{~mL}$ compared to $500 \mathrm{~mL}$ acceptor volume, which is consistent with $50 \mathrm{~mL}$ having sufficient sink capacity for these extractions.

Extracting $0.5 \mathrm{~g}$ soil with $50 \mathrm{~mL}$ ethanol yields a solid to liquid ratio of 1:100 g/mL. However, the MEBE configuration will provide a much higher sink capacity compared to traditional HPCD extractions with the same soil-to-liquid ratio, since ethanol has a much higher capacity for PAHs compared to HPCD solutions. The sink capacity of MEBE is also higher compared to sorptive bioaccessibility extraction methods with silicone sinks ${ }^{9}$, as the sink capacity of $50 \mathrm{~mL}$ ethanol corresponds to $144 \mathrm{~mL}$ (NAP) to $316 \mathrm{~mL}$ (BaP) silicone $\left(\mathrm{V}_{\mathrm{PDMS}}=\mathrm{V}_{\mathrm{EtOH}} \times \mathrm{K}_{\mathrm{EtOH}, \mathrm{PDMS}}, \mathrm{Table} 1\right)$. Soot, biochar and some types of historically polluted soils can have extremely high solid to water distribution coefficients $\left(K_{D}, L / k g\right)$, which then also requires the acceptor phase to provide a very high sink capacity ${ }^{12}$. A solid to volume ratio of $1: 100 \mathrm{~g} / \mathrm{mL}$ might not always provide sufficient sink capacity for all kinds of samples and contaminants. However, for new types of environmental samples it is straightforward to vary the acceptor volume and find the needed sink capacity, as done here. Sorptive sinks should not only have sufficient sink capacity, they should also be sufficiently fast in removing the desorbed molecules from the aqueous solution, rendering the desorption process the rate limiting step. This calls for a high sink surface area relative to the desorption medium volume $(A / V)$, which is intrinsic for bioaccessibility extraction methods with Tenax beads but more difficult to achieve when using, e.g., a piece of polymer sheet, a polymer rod or a sorbent disk. In the present study, we maximized this $A / \mathrm{V}$ ratio by positioning a small volume of soil suspension within the LDPE membrane bag, which is in contrast to other 
methods where a sorptive sink is submerged within a much larger volume of soil suspension. The A/V ratio of MEBE was plotted against its sink to sample mass ratio and compared to other recent bioaccessibility extraction methods with sorptive sinks (Figure 2). This illustrates that the MEBE approach indeed combines a high $\mathrm{A} / \mathrm{V}$ ratio with a high capacity ratio.

\section{Diffusion characterization}

The mass transfer resistance through the LDPE membrane was studied by adding $100 \mu \mathrm{L}$ acetonitrile solution (CRM47940) containing the 16 US EPA priority PAHs at the $10 \mathrm{mg} / \mathrm{L}$ level to the LDPE bags and then monitoring the PAH release into the ethanol acceptor solution. A rate constant $\left(k, h^{-1}\right)$ was calculated by fitting the mass transfer profiles to a first order exponential function $\left(A=A_{0}(1-\exp (-k t))\right)$, where $A$ is the extracted mass at time $t$ normalized against the maximum mass measured at $96 \mathrm{~h}$ (Figure SI1). The $\mathrm{t}_{95}$ value $\left(t_{95 \%}=\ln (20) / k\right)$ describes the estimated time for transferring $95 \%$ of the PAH mass to the acceptor solution, and ranged from $10 \mathrm{~h}$ for naphthalene to $47 \mathrm{~h}$ for indeno(1,2,3-cd)pyrene (Table SI2), but the presence of each PAH could be detected in the acceptor solution within $3 \mathrm{~h}$ (Figure SI1). Overall, all PAHs were quantitatively transferred to the acceptor solution within 2 days. The mass transfer time through the membrane sets some limitations regarding short term bioaccessibility extractions when measuring only the mass of PAHs in the ethanol. However, it is rather simple to empty the LDPE device and extract PAHs from the small mass of LDPE, which then allows short term measurements of bioaccessibility based on the sum of PAH mass in ethanol and membrane.

\section{Influence of agitation mode}

During optimization of the MEBE method, the mass transfer of PAHs from "Landfill" soil to the ethanol acceptor phase was monitored under different shaking regimes, using fluoranthene as a model compound (highly abundant in all test soils). Kinetic profiles obtained are illustrated in Figure SI2. 
The mass transfer from soil to acceptor solution was found to depend on the agitation mode. Rolling of closed vials in horizontal position resulted in the highest mass transfer. The rolling of vials (1) is practical even for a large number of parallel systems, (2) creates reproducible conditions within and between experiments and (3) appears a rather gentle treatment that does not impose physical stress on the soil matrix or the LDPE membranes. Rolling of closed vials was thus selected as agitation mode in the final application of MEBE on PAH polluted soils.

\section{Ethanol permeation experiment}

The permeability of ethanol across the LDPE membrane was tested under MEBE experimental conditions. The ethanol content in the HPCD solution was for this purpose measured as a function of time. The ethanol concentration in the HPCD solution increased linearly with time and was $10.3 \pm 0.5 \%(v / v, n=3)$ and 19.9 $\pm 1.7 \%(v / v, n=3)$ after respectively 7 and 14 days (Figure $S \mid 3)$. This implied a negligible co-solvent effect in the first days of the bioaccessibility extraction, which then continuously increases during the course of the bioaccessibility extraction. The ethanol effect on the bioaccessibility extraction process was assessed based on partitioning calculations, which showed an only minor effect of $20 \%$ ethanol on the capacity of the mobilization medium for representative PAHs (Table 1). $20 \%$ of ethanol enhances the capacity of pure water by factor 4 for naphthalene and 22 for benzo(a)pyrene, which is much lower compared to the capacity enhancement by the HPCD carrier ${ }^{34}$. The capacity enhancement effect of $10-20 \%$ of ethanol will thus be very limited in the HPCD solutions that already have a high capacity for PAHs. The capacity enhancement of both $20 \%$ ethanol and HPCD is orders of magnitude lower compared to the capacity enhancement by pure ethanol (factor 2500 for NAP \& 1900000 for BaP, Table 1). Further, we do not expect that $20 \%$ ethanol increases desorption from the soil by acting as competitive sorbate as reported for toluene $^{35}$, since competitive (de)sorption of PAHs generally requires an aromatic moiety to form $\pi-\pi$ bonds at the high affinity sorption site. Recently, Humel and co-workers reported that atmospheric carbonation 
can reduce the bioaccessibility of PAHs in industrially contaminated soil, and that lowering the $\mathrm{pH}$ of the mobilization medium then can lead to a re-mobilisation ${ }^{36}$. We do not expect that $10-20 \%$ of ethanol do mobilize PAHs by this mechanism, since the ethanol addition to water is largely $\mathrm{pH}$ neutral.

\section{Membrane enhancement of bioaccessibility extraction}

The mass of PAH released into $50 \mathrm{~mL}$ ethanol normalized to the soil sample mass in the LDPE bag ( $\mu \mathrm{g}$ PAH/g soil) was determined and plotted against the extraction time. Data for fluoranthene as model PAH are presented in Figure 3. The mass of PAH released in HPCD extractions without a sink was also determined and included in the same plot. Despite the short lag introduced by the diffusion through the membrane, the mass of PAHs extracted by the new MEBE approach, in which the sink was separated from the extraction medium, was in all instances greater $(p<0.05)$ than for HPCD extraction (Table SI3). While PAH desorption during conventional HPCD extractions appeared to stop after a few days, the mass flux from soil to ethanol in MEBE was sustained throughout the test period.

\section{Application of MEBE to four field contaminated soils}

MEBE extractions were performed on four industrially contaminated soils to verify the applicability of this method to real world samples. The mass ratios of individual PAHs between ethanol extract and initial total content of the soil sample were fairly similar for "Vienna, street" and "Vienna, bridge" (Figure 4a,c), with concentrations of most individual PAHs in ethanol extracts of the first four days being below the analytical limit of quantification. Soil "Vienna, train station" differed as 7 out of 10 occurring PAHs could be detected already in "day 4" extracts although generally in low concentrations (Figure 4b). This may be explained by the history of this site that harbored a tar deposit rather than tar or gas production facilities. Consequently, it is not likely that high affinity materials, such as coal, coke or charred matter, that are capable of significantly reducing PAH accessibility, have been introduced in this soil" ${ }^{35}$. MEBE results of "Vienna, landfill" (model soil) differed strongly from the other three soils (Figure 4d). Most of the PAHs could be 
determined already on the first day of MEBE (8 out of 11 occurring PAHs). Unlike the other soils, "Vienna, landfill" did not show a pronounced increase in $C / C_{\text {total }}$ ratios at day 14 . Still, when comparing the PAH mass ratios from day 9 and day 14 using the Wilcoxon matched pairs test, statistically significant differences for all four soils were observed $(p<0.05)$. Extraction times were not extended beyond two weeks to avoid that an elevated ethanol content inside the bag could unintentionally enhance the PAH desorption and lead to an overestimation of bioaccessibility. For an overall comparison of MEBE against conventional HPCD extraction, the average bioaccessible fraction ( $A B F)$, normalized to the mass of soil, was calculated in each of the four soils by dividing the sum of accessible mass of US EPA PAHs by the sum of total mass of individual PAHs as measured after exhaustive extraction (Table SI4). For all soils, ABF at day 14 was at least double for MEBE when compared to conventional HPCD extraction. Unlike MEBE, the HPCD method was unable to detect PAH accessibility for soil "Vienna, train station". When restricting the extraction period to six days only, ABF for soils "Vienna, street" and "Vienna, bridge" were 1.4 and 2.2 times higher in HPCD extracts compared to MEBE ethanol extracts. However, for the remaining soils conventional HPCD extraction revealed no extraction ("Vienna, train station") or a 4.7 times lower ABF ("Vienna, landfill") at day 6. In addition, MEBE resulted in a higher number of accessible PAHs (6/10 to 12/12) against HPCD extraction (namely, $0 / 10$ to $6 / 10$ ), which can best be explained by a combination of better extraction capacity of MEBE and its inherent clean-up (membrane extraction) that leads to a better signal to noise ratio (Table SI4). For high molecular weight PAHs with a log $\mathrm{K}_{\mathrm{ow}}>6$, MEBE yielded measurements of PAHs that were not detected in HPCD solutions (results not shown).

The detection power of the MEBE method can easily be increased by 1-2 orders of magnitude by simple evaporative enrichment of the final acceptor solution. However, no enrichment was included in the present study, since direct injection of ethanol extracts into HPLC with fluorescence detection generally provided sufficient analytical sensitivity. 
The developed MEBE method provides an operational time window in the order of 2-7 days, which however easily can be extended. The lower time limit was set by the time required for a quantitative PAH transfer over the LDPE membrane (1-2 days), which makes short-term measurements in the ethanol acceptor less meaningful. However, it is rather simple to extend the applicability domain to shorter extraction times by eluting PAHs from the cleaned LDPE membrane and summing up PAH masses in ethanol and membrane. The small mass and high surface area of the LDPE membrane allows a faster elution of PAHs when compared to the silicone rod methodology.

The upper time limit was set by the permeation of ethanol into the LDPE bag that resulted in ethanol concentrations of 10 and $20 \%$ after one and two weeks, making bioaccessibility extractions of more than 1 or 2 weeks less meaningful although providing conservative estimates of the bioaccessible share. Changing the acceptor solvent seems the most straightforward approach to extend this upper time limit, which however might lead to more sample preparation prior to the instrumental analysis. For instance, the purified plant oil "miglyol" has very good solubilizing properties for $\mathrm{PAHs}^{37}$ and will to a much lesser degree permeate through the membrane. This would reduce the mass flux of acceptor solvent into the LDPE bag, while at the same time increasing the resemblance of MEBE with the uptake of HOCs into animals and humans, which not only involves a passage over a membrane but also the subsequent partitioning into storage lipids.

\section{CONCLUSIONS}

MEBE offers a paradigm shift in bioaccessibility extraction by separating desorption medium and acceptor solution with a semipermeable membrane, which allows the independent control of desorption conditions and sink capacity. This can be utilized to provide relevant desorption conditions in combination with infinite sink capacity to comply with the requirement of ISO 17402:2008 for actual worst-case extraction scenarios. 
Benefits of MEBE, as compared to conventional cyclodextrin extractions, include a much higher and scalable sink capacity, a cleaner extract that can be injected directly into HPLC, a drastic reduction of sample manipulation and the possibility of processing many samples simultaneously since the setup is readily arranged in standard vials that can be automatically processed by autosamplers, thus minimizing analyst workload and interaction with the sample. The next step should be adjusting and tailoring the MEBE approach for specific exposure scenarios and conditions, and particularly the physiological uptake of hydrophobic organic pollutants in humans and animals.

\section{ACKNOWLEDGEMENTS}

The authors acknowledge financial support through two MACATA projects (EFRE \& Lower Austria WST3-T95/017-2012 and Lower Austria WST3-T-95/025-2014). Manuel Miró acknowledges financial support from the Spanish State Research Agency (AEI) through projects CTM2014-56628-C3-3-R (AEI/FEDER, UE), CTM2014-61553-EXP (AEI/FEDER, UE) and CTM2017-84763-C3-3-R (AEI/FEDER, UE). David J. Cocovi-Solberg extends his appreciation to the Spanish Ministry of Economy and Competitiveness for an FPI scholarship and mobility grant for a research stay at DTU. The authors express their gratitude to Marion SumetzbergerHasinger for performing PAH analysis of industrially contaminated soils and related MEBE extracts. 
Tables

Table 1: Partition coefficients of representative PAHs for the phases water (w), ethanol (EtOH), aqueous solution with $\mathrm{x} \%$ ethanol (X\% EtOH) and Polydimethylsiloxane (PDMS) as calculated using the UFZ-LSER database. $\mathrm{K}_{\mathrm{EtOH}, \mathrm{w}}$ denotes the partition coefficient between dry $100 \%$ ethanol and water.

\begin{tabular}{|lrrrrrrr|} 
& Log $K_{\text {EtOH,w }}$ & Log $K_{\text {PDMS,w }}$ & Log $_{\text {EtOH,PDMs }}{ }^{a}$ & Log $K_{10 \% \text { EtOH,w }}$ & Log $K_{20 \% \text { EtOH,w }}$ & Log $K_{50 \% \text { EtOH,w }}$ \\
\hline NAP & 3.40 & 2.94 & 0.46 & 0.22 & 0.61 & 1.99 \\
\hline PHE & 4.72 & 4.14 & 0.58 & 0.36 & 0.94 & 2.81 \\
\hline ANT & 4.75 & 4.20 & 0.55 & 0.33 & 0.92 & 2.75 \\
\hline PYR & 5.26 & 4.66 & 0.60 & 0.38 & 1.05 & 3.09 \\
\hline BaA & 5.73 & 4.95 & 0.78 & 0.47 & 1.22 & 3.48 \\
\hline CHR & 6.06 & 5.38 & 0.68 & 0.49 & 1.25 & 3.62 \\
\hline BaP & 6.29 & 5.49 & 0.80 & 0.50 & 1.34 & 3.78 \\
\hline
\end{tabular}

${ }^{a}$ calculated by subtracting Log $\mathrm{K}_{\mathrm{EtOH}, \mathrm{w}}$ by Log $\mathrm{K}_{\mathrm{PDMS}, \mathrm{w}}$ 


\section{FIGURE CAPTIONS}

420

Figure 1. Membrane enhanced bioaccessibility extraction (MEBE) of historically polluted soil for 8 days at varying acceptor volume. The extracted masses of individual PAHs are shown for 5,50 and $500 \mathrm{~mL}$ ethanol acceptor volume ( $n=3$, mean \pm standard deviation $)$.

425 Figure 2. For different sorptive sink approaches ${ }^{9,11,16,17,38,39}, \mathrm{~A} / \mathrm{V}$ ratios between sink surface area and desorption medium volume $\left(\mathrm{A}_{\text {sink }} / \mathrm{V}_{\text {solution }}\right)$ are plotted against their capacity ratio $\left(\mathrm{m}_{\text {sink }} / \mathrm{m}_{\text {soil }}\right)$. High $\mathrm{A} / \mathrm{V}$ ratios provide fast mass transfer of analytes from the desorption solution to the sink, and high capacity ratios are crucial for samples with high $K_{D}$ values. MEBE combines a high $A / V$ ratio with a high capacity ratio.

Figure 3. The mass flux of fluoranthene from $0.5 \mathrm{~g}$ soil into $50 \mathrm{~mL}$ acceptor solution is shown for MEBE extraction and HPCD extraction. The mass flux from the soil and into the ethanol (MEBE) was larger and lasted longer compared to the HPCD solution.

Figure 4: Bioaccessible fractions of 12 US EPA PAHs in four industrially contaminated soils between 1 and 14 days as assessed with MEBE; columns marked with a are calculated with 2 replicates; error bars represent Standard Error of the Mean $(n=3-5)$; ANT and DhA were below detection limits for some soils; the dotted line indicates a bioaccessible fraction of $25 \%$. Names of PAHs as associated to abbreviations are given in Table SI1. 


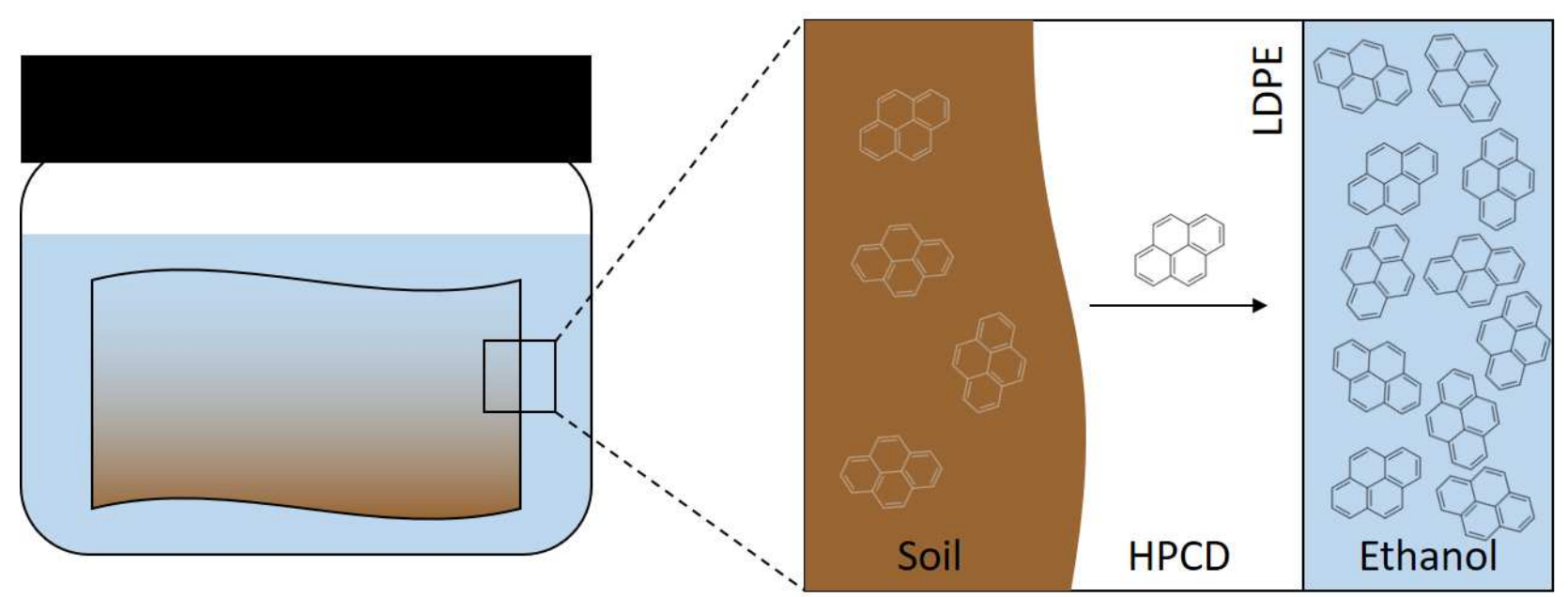

TOC Figure

445 


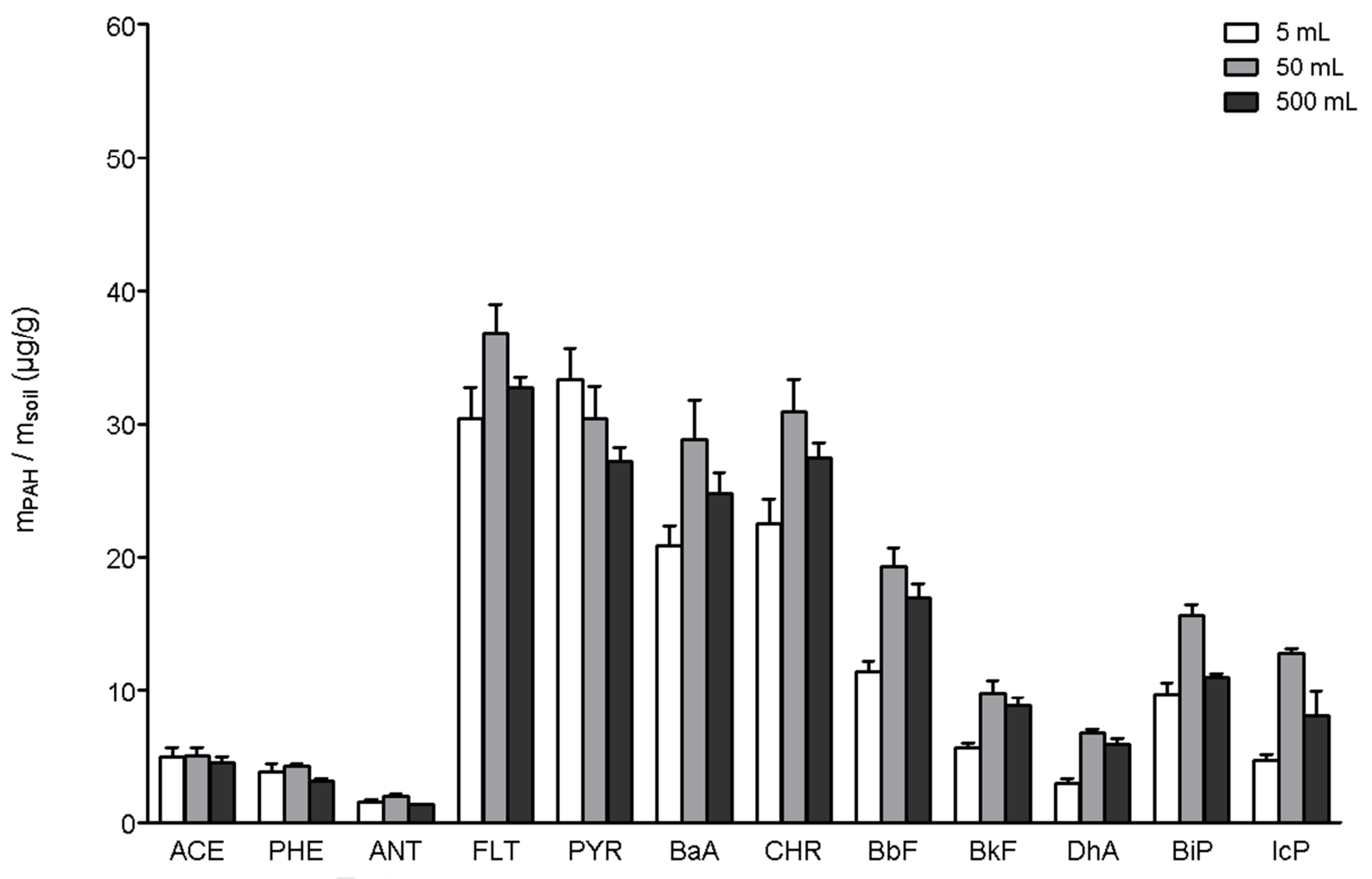

Figure 1 


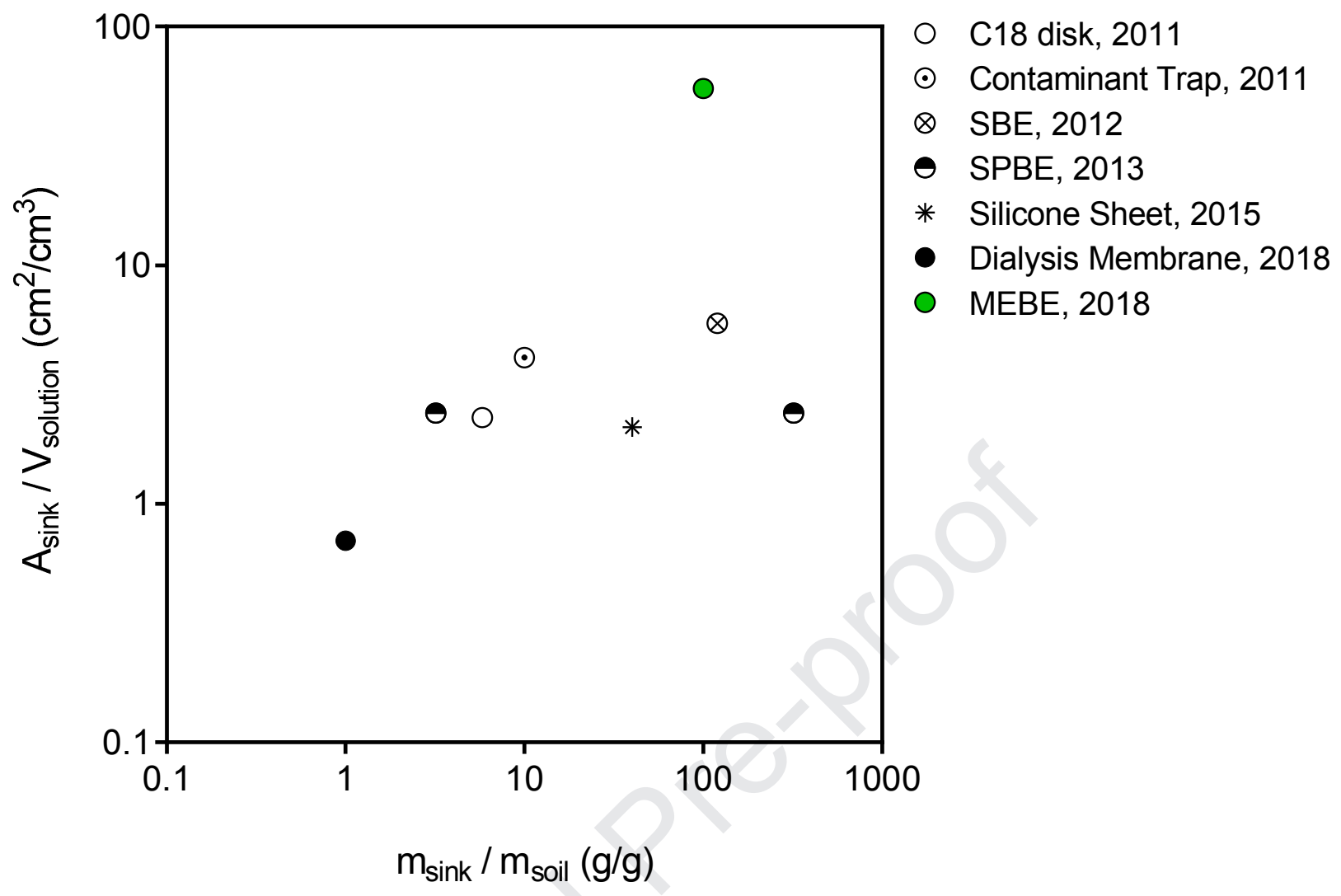

Figure 2 


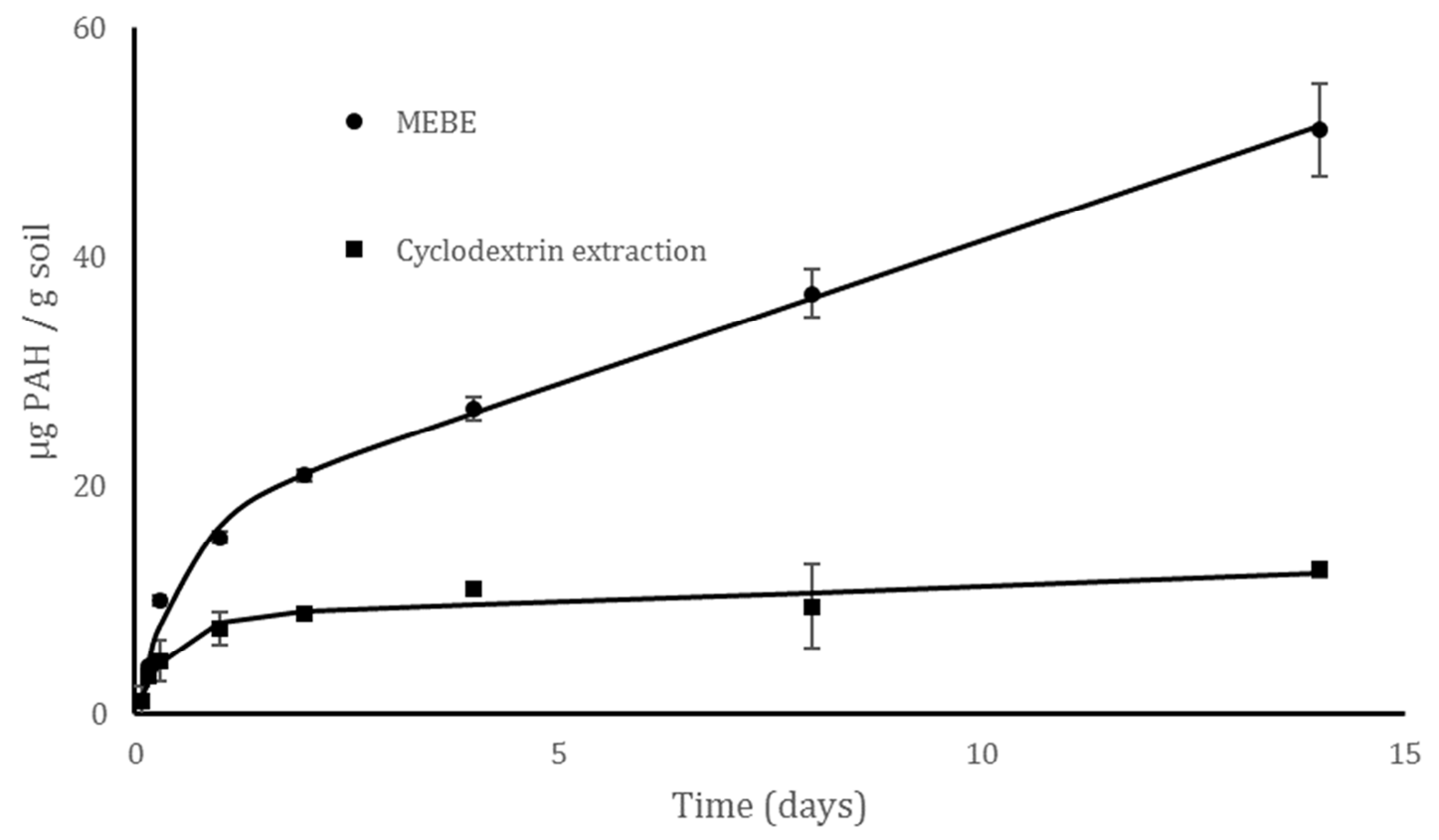

$460 \quad$ Figure 3 

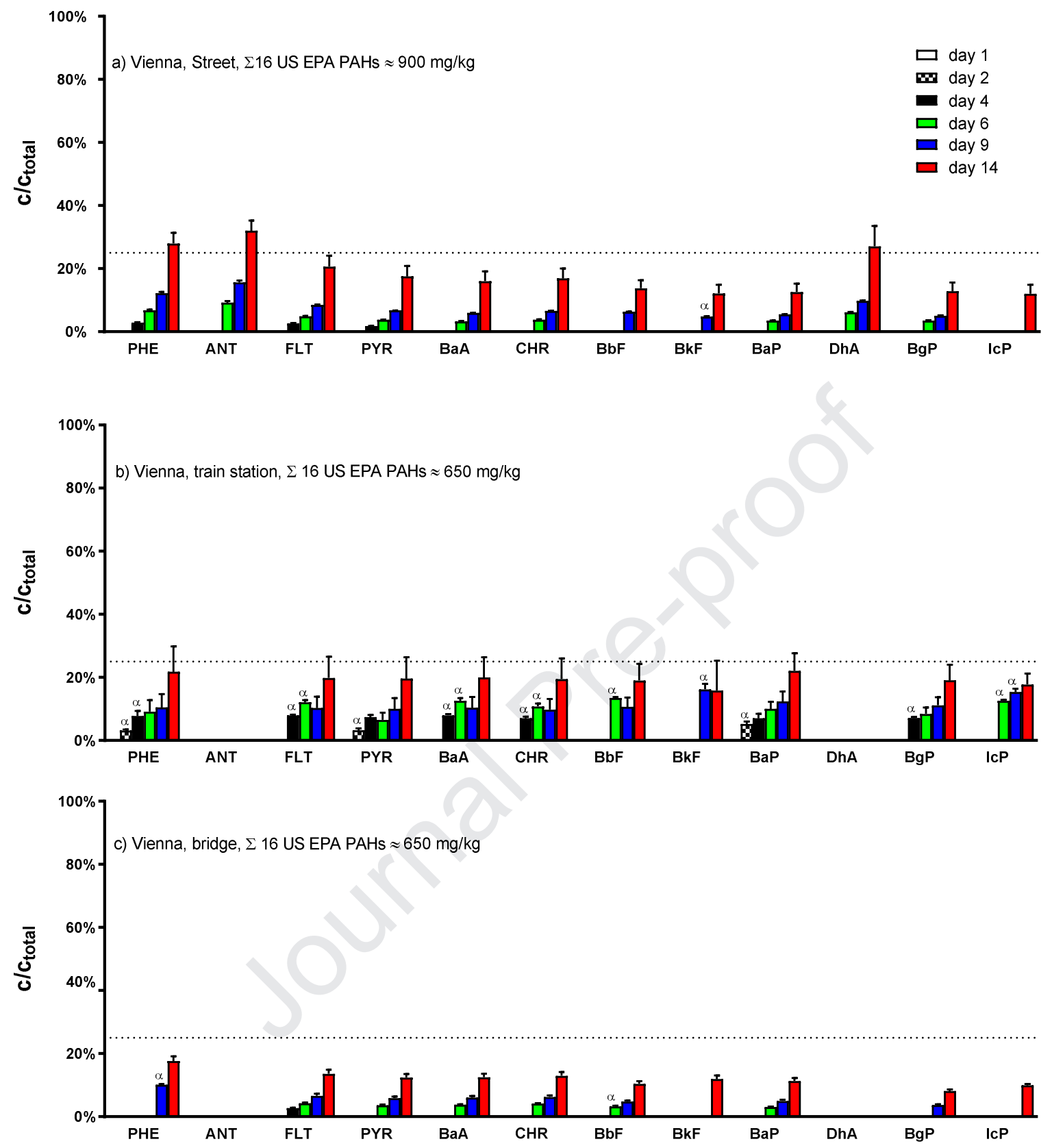


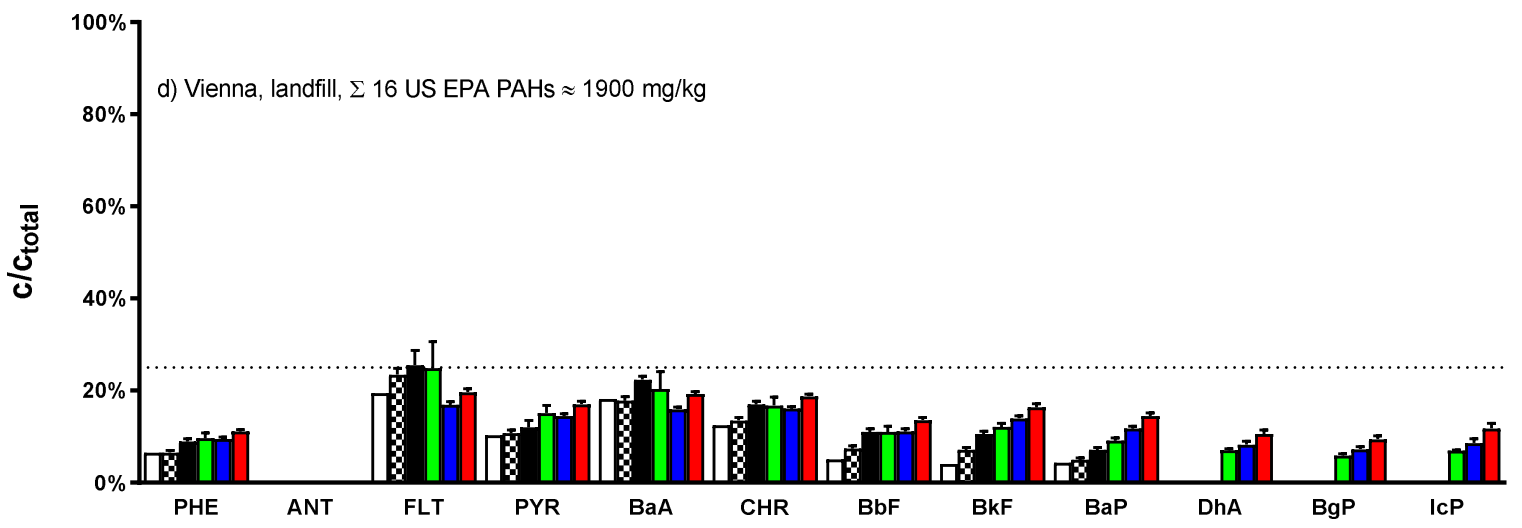

Figure 4 


\section{REFERENCES}

(1) Fedotov, P. S.; Kördel, W.; Miró, M.; Peijnenburg, W. J. G. M. G. M.; Wennrich, R.; Huang, P.-M. M. Extraction and Fractionation Methods for Exposure Assessment of Trace Metals, Metalloids, and Hazardous Organic Compounds in Terrestrial Environments. Crit. Rev. Environ. Sci. Technol. 2012, 42 (11), 1117-1171. https://doi.org/10.1080/10643389.2011.556544.

(2) Reichenberg, F.; Karlson, U. G.; Gustafsson, Ö.; Long, S. M.; Pritchard, P. H.; Mayer, P.; Gustafsson, O.; Long, S. M.; Pritchard, P. H.; Mayer, P. Low Accessibility and Chemical Activity of PAHs Restrict Bioremediation and Risk of Exposure in a Manufactured Gas Plant Soil. Environ. Pollut. 2010, 158 (5), 1214-1220. https://doi.org/10.1016/j.envpol.2010.01.031.

475 (3) Alexander, M. Aging, Bioavailability, and Overestimation of Risk from Environmental Pollutants. Environ. Sci. Technol. 2000, 34 (20), 4259-4265.

(4) Xia, H.; Gomez-Eyles, J. L.; Ghosh, U. Effect of Polycyclic Aromatic Hydrocarbon Source Materials and Soil Components on Partitioning and Dermal Uptake. Environ. Sci. Technol. 2016, 50 (7), 3444-3452. https://doi.org/10.1021/acs.est.5b06164.

480 (5) Ortega-Calvo, J.-J.; Harmsen, J.; Parsons, J. R.; Semple, K. T.; Aitken, M. D.; Ajao, C.; Eadsforth, C.; Galay-Burgos, M.; Naidu, R.; Oliver, R.; Peijnenburg, W. J. G. M.; Römbke, J.; Streck, G.; Versonnen, B. From Bioavailability Science to Regulation of Organic Chemicals. Environ. Sci. Technol. 2015, 49 (17), 10255-10264. https://doi.org/10.1021/acs.est.5b02412.

(6) Reichenberg, F.; Mayer, P. Two Complementary Sides of Bioavailability: Accessibility and Chemical Activity of Organic Contaminants in Sediments and Soils. Environ. Toxicol. Chem. 2006, 25 (5), 12391245.

(7) Cipullo, S.; Prpich, G.; Campo, P.; Coulon, F. Assessing Bioavailability of Complex Chemical Mixtures in Contaminated Soils: Progress Made and Research Needs. Sci. Total Environ. 2018, 615, 708-723. https://doi.org/10.1016/j.scitotenv.2017.09.321.

490 (8) Cui, X.; Mayer, P.; Gan, J. Methods to Assess Bioavailability of Hydrophobic Organic Contaminants: Principles, Operations, and Limitations. Environ. Pollut. 2013, 172, 223-234. https://doi.org/10.1016/j.envpol.2012.09.013.

(9) Gouliarmou, V.; Mayer, P. Sorptive Bioaccessibility Extraction (SBE) of Soils: Combining a Mobilization Medium with an Absorption Sink. Environ. Sci. Technol. 2012, 46 (19), 10682-10689.

495 https://doi.org/10.1021/es301515s.

(10) Collins, C. D.; Mosquera-Vazquez, M.; Gomez-Eyles, J. L.; Mayer, P.; Gouliarmou, V.; Blum, F. Is There Sufficient 'Sink'in Current Bioaccessibility Determinations of Organic Pollutants in Soils? Environ. Pollut. 2013, 181, 128-132.

(11) Zhang, Y.; Pignatello, J. J.; Tao, S.; Xing, B. Bioacessibility of PAHs in Fuel Soot Assessed by an in Vitro Digestive Model: Effect of Including an Absorptive Sink. Environ. Sci. Technol. 2015, 49 (6), 3905-3912. https://doi.org/10.1021/es505898v.

(12) Mayer, P.; Hilber, I.; Gouliarmou, V.; Hale, S. E.; Cornelissen, G.; Bucheli, T. D. How to Determine the Environmental Exposure of PAHs Originating from Biochar. Environ. Sci. Technol. 2016, 50 (4), 19411948. https://doi.org/10.1021/acs.est.5b05603.

(13) Bartolomé, N.; Hilber, I.; Sosa, D.; Schulin, R.; Mayer, P.; Bucheli, T. D. Applying No-Depletion Equilibrium Sampling and Full-Depletion Bioaccessibility Extraction to 35 Historically Polycyclic Aromatic Hydrocarbon Contaminated Soils. Chemosphere 2018, 199, 409-416. https://doi.org/10.1016/j.chemosphere.2018.01.159.

(14) Cornelissen, G.; Gustafsson, Ö.; Bucheli, T. D.; Jonker, M. T. O.; Koelmans, A. A.; van Noort, P. C. M. Extensive Sorption of Organic Compounds to Black Carbon, Coal, and Kerogen in Sediments and Soils: Mechanisms and Consequences for Distribution, Bioaccumulation .... Environ. Sci. Technol. 2005, 39 (18), 6881-6895.

(15) Hale, S. E.; Arp, H. P. H.; Kupryianchyk, D.; Cornelissen, G. A Synthesis of Parameters Related to the 
Binding of Neutral Organic Compounds to Charcoal. Chemosphere 2016, 144, 65-74. https://doi.org/10.1016/j.chemosphere.2015.08.047.

(16) Mayer, P.; Olsen, J. L.; Gouliarmou, V.; Hasinger, M.; Kendler, R.; Loibner, A. P. A Contaminant Trap as a Tool for Isolating and Measuring the Desorption Resistant Fraction of Soil Pollutants. Environ. Sci. Technol. 2011, 45 (7), 2932-2937. https://doi.org/10.1021/es1033124.

(17) Gouliarmou, V.; Collins, C. D.; Christiansen, E.; Mayer, P. Sorptive Physiologically Based Extraction of Contaminated Solid Matrices: Incorporating Silicone Rod as Absorption Sink for Hydrophobic Organic Contaminants. Environ. Sci. Technol. 2013, 47 (2), 941-948. https://doi.org/10.1021/es303165u.

(18) Li, C.; Cui, X. Y.; Fan, Y. Y.; Teng, Y.; Nan, Z. R.; Ma, L. Q. Tenax as Sorption Sink for in Vitro Bioaccessibility Measurement of Polycyclic Aromatic Hydrocarbons in Soils. Environ. Pollut. 2015, 196, 47-52. https://doi.org/10.1016/j.envpol.2014.09.016.

(19) Van der Heijden, S. A.; Jonker, M. T. O. PAH Bioavailability in Field Sediments: Comparing Different Methods for Predicting in Situ Bioaccumulation. Environ. Sci. Technol. 2009, 43 (10), 3757-3763. https://doi.org/10.1021/es803329p.

(20) Frišták, V.; Laughinghouse, H. D.; Packová, A.; Graser, M.; Soja, G. Monitoring of Methylated Naphthalenes in Sludge-Derived Pyrogenic Carbonaceous Materials. Chemosphere 2019, 217, 456462. https://doi.org/10.1016/j.chemosphere.2018.11.030.

(21) Fang, M.; Stapleton, H. M. Evaluating the Bioaccessibility of Flame Retardants in House Dust Using an in Vitro Tenax Bead-Assisted Sorptive Physiologically Based Method. Environ. Sci. Technol. 2014, 48 (22), 13323-13330. https://doi.org/10.1021/es503918m.

(22) Rusina, T. P.; Smedes, F.; Klanova, J. Diffusion Coefficients of Polychlorinated Biphenyls and Polycyclic Aromatic Hydrocarbons in Polydimethylsiloxane and Low-Density Polyethylene Polymers. J. Appl. Polym. Sci. 2010, 116 (3), 1803-1810. https://doi.org/10.1002/app.31704.

(23) Jönsson, J. Å.; Mathiasson, L. Memrane Extraction in Analytical Chemistry. J. Sep. Sci. 2001, 24 (7), 495-507. https://doi.org/10.1002/1615-9314(20010801)24:7<495::AID-JSSC495>3.0.CO;2-B.

(24) Carasek, E.; Merib, J. Membrane-Based Microextraction Techniques in Analytical Chemistry: A Review. Anal. Chim. Acta 2015, 880, 8-25. https://doi.org/10.1016/j.aca.2015.02.049.

(25) Jakubowska, N.; Polkowska, Ż.; Namieśnik, J.; Przyjazny, A. Analytical Applications of Membrane Extraction for Biomedical and Environmental Liquid Sample Preparation. Crit. Rev. Anal. Chem. 2005, 35 (3), 217-235. https://doi.org/10.1080/10408340500304032.

(26) Strandberg, B.; Bergqvist, P. A.; Rappe, C. Dialysis with Semipermeable Membranes as an Efficient Lipid Removal Method in the Analysis of Bioaccumulative Chemicals. Anal. Chem. 1998, 70 (3), 526-533.

(27) Mayer, P.; Fernqvist, M. M.; Christensen, P. S.; Karlson, U.; Trapp, S. Enhanced Diffusion of Polycyclic Aromatic Hydrocarbons in Artificial and Natural Aqueous Solutions. Environ. Sci. Technol. 2007, 41 (17), 6148-6155. https://doi.org/10.1021/es070495t.

(28) Fernandez, L. A.; MacFarlane, J. K.; Tcaciuc, A. P.; Gschwend, P. M. Measurement of Freely Dissolved PAH Concentrations in Sediment Beds Using Passive Sampling with Low-Density Polyethylene Strips. Environ. Sci. Technol. 2009, 43 (5), 1430-1436.

(29) Austrian Standards Institute - DIN 4220:2017. 2018.

(30) Reid, B. J.; Stokes, J. D.; Jones, K. C.; Semple, K. T. Nonexhaustive Cyclodextrin-Based Extraction Technique for the Evaluation of PAH Bioavailability. Environ. Sci. Technol. 2000, 34 (15), 3174-3179. 555 https://doi.org/10.1021/es990946c.

(31) Cuypers, C.; Pancras, T.; Grotenhuis, T.; Rulkens, W. The Estimation of PAH Bioavailability in Contaminated Sediments Using Hydroxypropyl-Beta-Cyclodextrin and Triton X-100 Extraction Techniques. Chemosphere 2002, 46 (8), 1235-1245.

(32) UFZ - LSER Database https://www.ufz.de/index.php?en=31698\&contentonly=1\&m=0\&lserd_data[mvc]=Public/start (accessed Aug 28, 2019).

(33) Moret, S.; Conte, L. S. A Rapid Method for Polycyclic Aromatic Hydrocarbon Determination in Vegetable Oils. J. Sep. Sci. 2002, 25 (1-2), 96-100. https://doi.org/10.1002/1615- 
9314(20020101)25:1/2<96::AID-JSSC96>3.0.CO;2-5.

565 (34) Gouliarmou, V.; Smith, K. E. C.; de Jonge, L. W.; Mayer, P. Measuring Binding and Speciation of Hydrophobic Organic Chemicals at Controlled Freely Dissolved Concentrations and without Phase Separation. Anal. Chem. 2012, 84 (3), 1601-1608. https://doi.org/10.1021/ac2028497.

(35) Humel, S.; Schmidt, S. N.; Sumetzberger-Hasinger, M.; Mayer, P.; Loibner, A. P. Enhanced Accessibility of Polycyclic Aromatic Hydrocarbons (PAHs) and Heterocyclic PAHs in Industrially Contaminated Soil after Passive Dosing of a Competitive Sorbate. Environ. Sci. Technol. 2017, 51 (14), 8017-8026. https://doi.org/10.1021/acs.est.7b01198.

(36) Humel, S.; Schritter, J.; Sumetzberger-Hasinger, M.; Ottner, F.; Mayer, P.; Loibner, A. P. Atmospheric Carbonation Reduces Bioaccessibility of PAHs in Industrially Contaminated Soil. J. Hazard. Mater. 2019, 121092. https://doi.org/10.1016/J.JHAZMAT.2019.121092.

575 (37) Mayer, P.; Toräng, L.; Glaesner, N.; Jönsson, J. A. Silicone Membrane Equilibrator: Measuring Chemical Activity of Nonpolar Chemicals with Poly(Dimethylsiloxane) Microtubes Immersed Directly in Tissue and Lipids. Anal. Chem. 2009, 81 (4), 1536-1542. https://doi.org/10.1021/ac802261z.

(38) Kademoglou, K.; Williams, A. C.; Collins, C. D. Bioaccessibility of PBDEs Present in Indoor Dust: A Novel Dialysis Membrane Method with a Tenax TA ${ }^{\circledR}$ Absorption Sink. Sci. Total Environ. 2018, 621, 1-8. https://doi.org/10.1016/j.scitotenv.2017.11.097.

(39) James, K.; Peters, R. E.; Laird, B. D.; Ma, W. K.; Wickstrom, M.; Stephenson, G. L.; Siciliano, S. D. Human Exposure Assessment: A Case Study of 8 PAH Contaminated Soils Using in Vitro Digestors and the Juvenile Swine Model. Environ. Sci. Technol. 2011, 45 (10), 4586-4593. https://doi.org/10.1021/es1039979. 


\section{Highlights}

- Bioaccessibility can be underestimated when the sink capacity is insufficient

- MEBE applies a membrane to separate desorption medium and analytical acceptor phase

- Desorption conditions and sink capacity can be varied and set almost independently

- MEBE minimizes sample preparation and yields extracts readily analyzable by HPLC

- The MEBE concept can be extended and applied to other samples and desorption media 
Editor in Chief Eddy Zeng, Jinan University, Guangzhou, China

"Membrane Enhanced Bioaccessibility Extraction (MEBE) of hydrophobic soil pollutants Using a semipermeable membrane for separating desorption medium and acceptor solvent"

Authors: David J. Cocovi-Solberg, Astrid Kellner, Stine N. Schmidt, Andreas Loibner, Manuel Miró \& Philipp Mayer

Dear Editor,

We hereby declare that we do not have any conflict of interest related to this submission.

Best regards and on behalf of all co-authors,

Philipp Mayer,

Corresponding Author

\section{Co-authors, main affiliation \& e-mail}

David J. Cocovi-Solberg, University of the Balearic Islands: dj.cocovi.solberg@gmail.com Astrid Kellner, Univ. of Natural Resources and Life Sciences Vienna: astrid.kellner@gmx.at Stine N. Schmidt, Technical University of Denmark: schmidt.stinen@epa.gov Andreas Loibner, Univ. of Natural Resources and Life Sciences Vienna: andreas.loibner@boku.ac.at Manuel Miró, University of the Balearic Islands: manuel.miro@uib.es Philipp Mayer, Technical University of Denmark: philm@env.dtu.dk 